\title{
A representação de questões ambientais em filmes de animação
}

Bianca Copello

(Aluna do curso de Comunicação Social/Cinema - PUC RJ)

\section{Introdução}

Não é de hoje que a sala de aula, livros e outros materiais didáticos deixaram de ser a única forma de aprendizado. Na realidade, conhecimentos sobre os mais diferentes assuntos podem ser adquiridos nos mais diferentes tipos de mídias existentes, sejam elas físicas ou digitais. E, muitas vezes, tais mídias ou plataformas de aprendizado nem sequer possuem como seu principal objetivo a intenção de serem didáticos. $O$ aprendizado se dá de forma muito mais eficaz e duradoura quando estamos aprendendo algo sem nos dar conta de que estamos aprendendo. Daí tem-se o conceito de aprendizado tangencial, muito utilizado hoje em dia como forma de ensino, seja por meio de jogos, quadrinhos, filmes e muito mais. Sendo assim, com base nisso, irei analisar a representação de questões ambientais em filmes de animação como forma de aprendizado e reflexão.

\section{Análise 1: "Princesa Mononoke"}




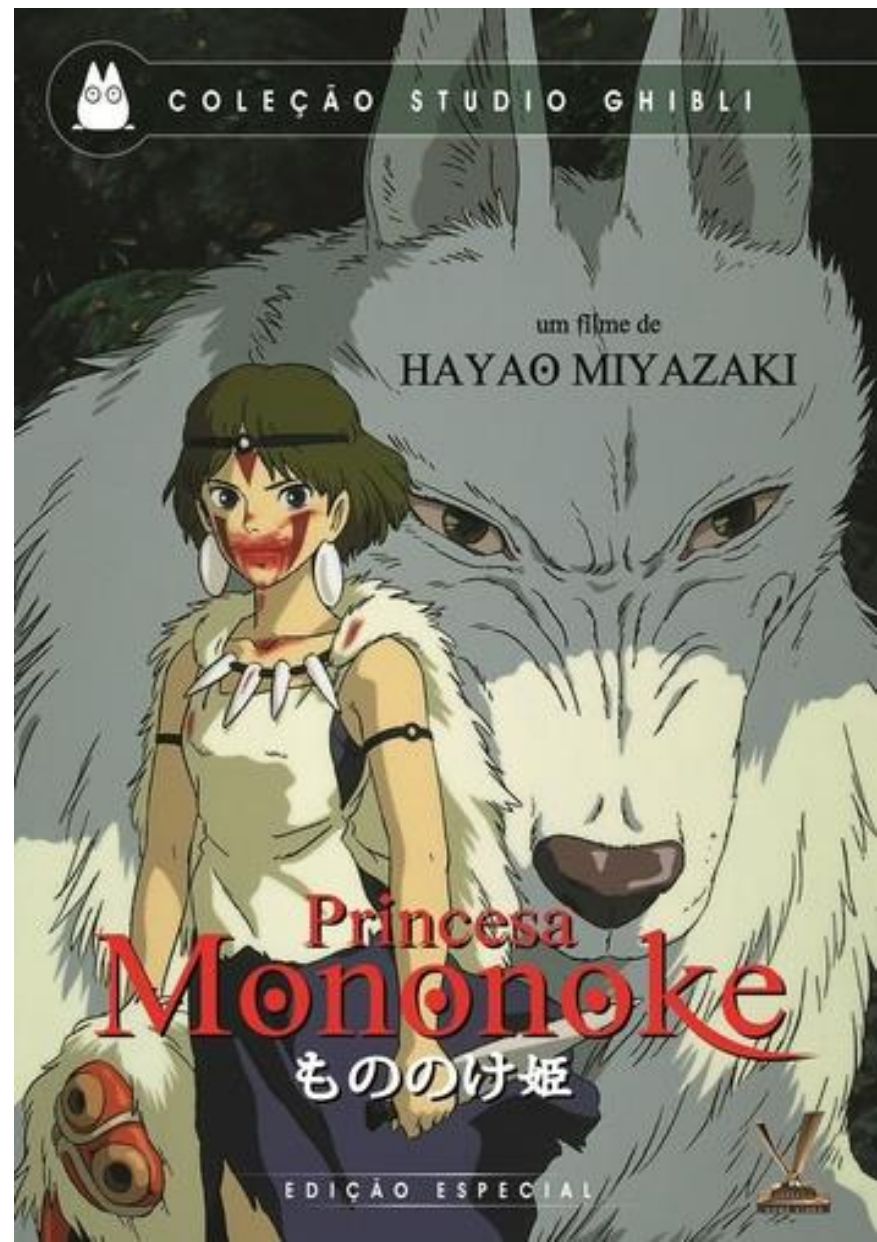

Poster do filme "Princesa Mononoke", 1999, dirigido por Hayao Miyazaki

O filme conta a história de Ashitaka, um jovem que foi amaldiçoado por um deus javali que ficou enfurecido ao ser baleado por uma bala de ferro, fruto da devastação humana na natureza. Com isso, Ashitaka deve abandonar a sua tribo e viajar pelo Japão medieval em busca de uma cura para a maldição que poderá levá-lo a morte.

Ao longo de sua aventura, Ashitaka se depara com muitos animais (espíritos da floresta), pessoas corruptas e ambiciosas que querem capturar esses animais para venda, uma aldeia liderada por uma mulher que, na realidade, se tratava de uma fábrica de armas cuja a sua líder foi a responsável por atirar no deus javali do início do filme e, a Princesa Mononoke, uma garota criada pelos lobos que se virou contra a sua própria espécie para se tornar a protetora da floresta. 
O filme retrata uma guerra entre a humanidade e a natureza, não apresentando um lado como totalmente certo ou errado, deixando isso ao encargo do espectador. A natureza é representada como um mundo de equilíbrio e harmonia, e, ao mesmo tempo em que é destruída de forma injusta pela ação humana também teimosa em aceitar a necessidade de algumas mudanças para a evolução da humanidade. Já, o lado dos humanos, é representado pela fábrica de armas liderada pela Lady Eboshi, mulher que fez de sua fábrica um abrigo para fugitivos e prostitutas quando o resto do mundo os negou os seus direitos humanos mais básicos.

Enquanto a guerra se desenrola, o protagonista Ashitaka se vê dividido entre ambos os lados, fazendo ações que, dependendo do caso, irão ajudar o lado humano liderado por Lady Eboshi e/ou o lado da natureza, liderado pela Princesa Mononoke. O filme tenta provocar a reflexão no espectador de que até que ponto nós devemos nos aproveitar da natureza para alcançar nossos objetivos e se não é possível alcançar um equilíbrio de forma que ambos os lados não saiam completamente prejudicados.

No fim do filme, o equilíbrio entre a humanidade e a natureza é alcançado graças a cooperação de Ashitaka e Mononoke, que se tornam as pontes entre os dois mundos.

\section{Análise 2: "O Lorax - Em busca da trúfula perdida"}




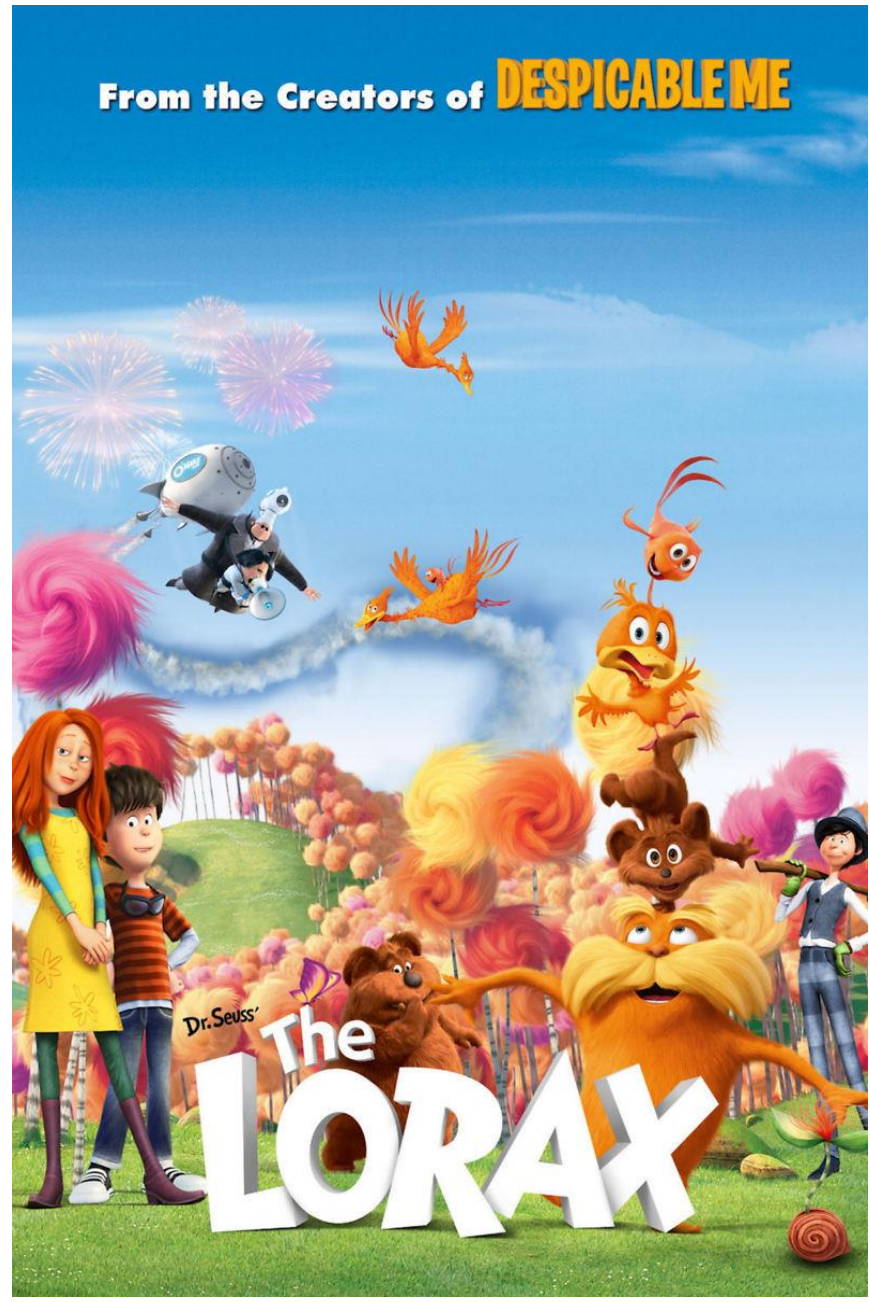

Poster do filme "O Lorax", 2012, dirigido por Chris Renaud

Ao contrário de Princesa Mononoke, O Lorax é um filme voltado para o público infantil e que tenta passar a mensagem de que mesmo as pequenas ações de uma única pessoa podem fazer a diferença no meio ambiente.

O filme se passa num mundo em que já não existem mais árvores e que além de imensas áreas de campos de natureza destruída existe apenas uma única cidade isolada que é feita totalmente de plástico. Nessa cidade há um empresário corrupto, que ganha muito vendendo aquilo que as pessoas não tem: ar puro. O protagonista da história, Ted, vive nessa cidade e é apaixonado por uma menina que possui o grande desejo de ver uma árvore de verdade. Motivado pelo seus sentimentos pela menina e guiado pelas fábulas de sua avó, Ted parte em busca daquele que poderia lhe contar o que aconteceu com as árvores e 
como conseguir uma: o velho Umavez-ildo, senhor que mora do lado de fora da cidade, junto da natureza destruída.

Durante as suas visitas constantes a casa do velho Umavez-ildo, Ted fica sabendo que as árvores desapareceram por conta das ações do próprio Umavez-ildo, que, no filme, representa os interesses e ambições da humanidade. Quando jovem, o Umavez-ildo cortou todas as árvores existentes com o interesse de produzir um produto para vender. Com isso, ele recebeu a visita de Lorax, o guardião da floresta, que fez de tudo para tentar alertá-lo das consequências de suas ações, porém, não foi o suficiente para detê-lo. O produto se tornou um sucesso e ele e sua família destruíram toda a natureza e habitat de várias espécies de animais. Nesse momento, o filme tenta provocar a reflexão de se é realmente necessário destruir tanto a natureza para conseguirmos aquilo que queremos. Sendo que, na realidade, nós também precisamos dela e deveríamos ser conscientes de até que ponto podemos utilizar os seus recursos.

Somente quando a última árvore é derrubada e que o Umavez-ildo não possui mais a principal matéria-prima para a fabricação do seu produto que ele percebe os danos que ele causou no mundo. Arrependido, se isola da sociedade, até o dia em que Ted vai visitá-lo pela primeira vez. Ao terminar de contar a sua história, o velho Umavez-ildo entrega a Ted a última semente que restou no mundo e o menino fica encarregado de plantá-la na cidade, num lugar onde todos possam ver.

O filme termina com Ted plantando a semente e relembrando para as pessoas a importância das árvores e da natureza. As árvores poderiam lhes dar o ar puro que era vendido corruptamente na cidade e remodelar todo o seu modo de vida. Os personagens cantam uma bela canção sobre preservação do meio ambiente enquanto plantam árvores pela cidade, a fim de reviver a natureza que foi um dia perdida. 


\section{Análise 3: "Nausicaä do Vale do Vento"}

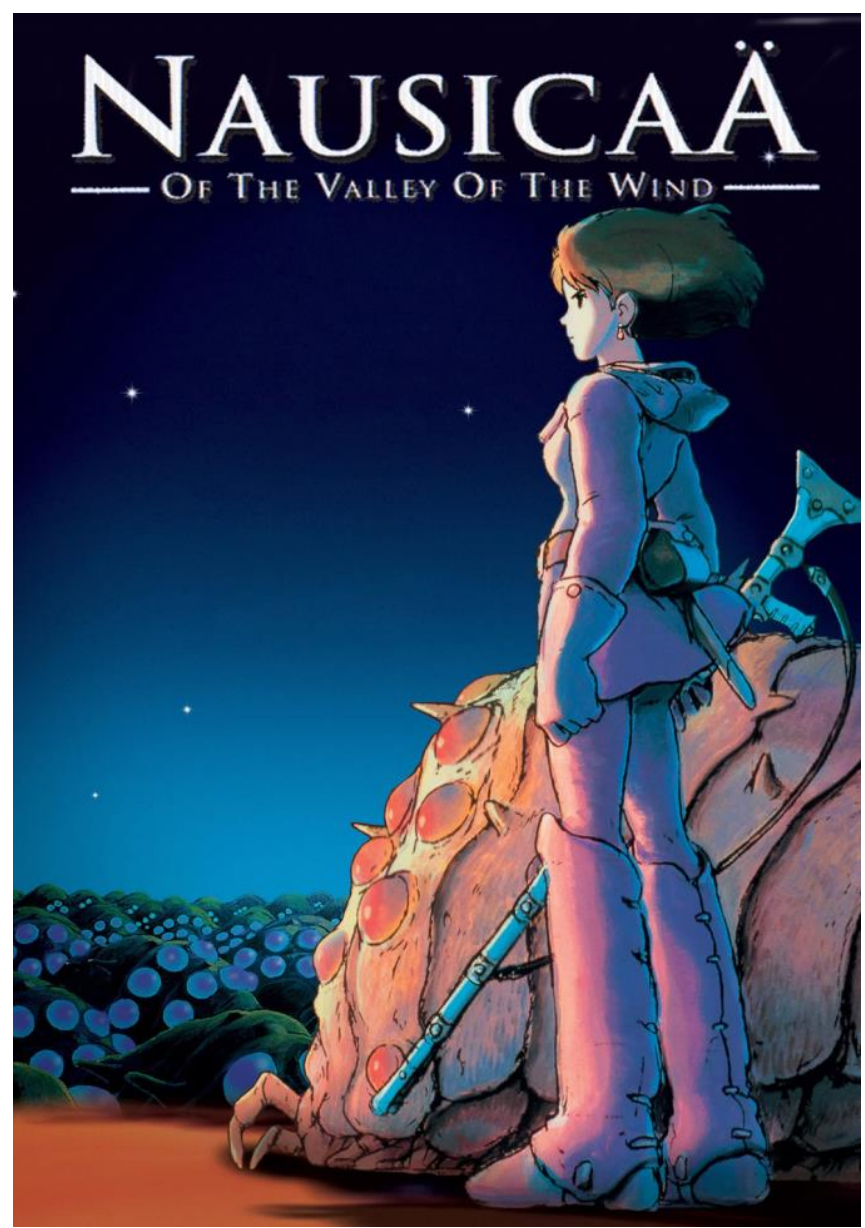

Poster do filme "Nausicaä do Vale do Vento", 1985, dirigido por Hayao Miyazaki

A história se passa mil anos depois do colapso da civilização industrial, num futuro pós-apocalíptico no qual a Terra teria passado pela "Guerra dos Sete Dias de Fogo". O resultado dessa guerra acarretou para o planeta a perda tecnológica, destruição do ecossistema, muito poluição, fome, mortes, além o fenômeno natural do "Mar do Declínio". Tal fenômeno se trata de um pântano emanado por gases tóxicos e insetos gigantes que está cobrindo aos poucos toda a superfície do planeta, ameaçando a sobrevivência humana.

Nausicaä, a protagonista do filme, é a princesa do Vale do Vento, um dos poucos povoados que sobreviveu à Guerra dos Sete Dias de Fogo. O Vale do Vento realiza todas as suas atividades através da energia eólica proveniente dos ventos que protegem o 
vilarejo, mostrando que uma sociedade pode ser auto suficiente com o uso de energias renováveis.

Neste mundo, após a grande poluição que se espalhou, o ar do Vale do Vento é um dos poucos ainda se encontra puro e que apresenta suas terras cultiváveis. Para circular livremente pelo mundo a foro as pessoas precisam sempre estar acompanhadas de uma máscara de gás, caso o contrário, seus pulmões apodreceriam em questões de segundos.

Por mais que a Guerra dos Sete Dias de Fogo já tenha cessado, o filme mostra que os povoados sobreviventes continuam guerreando entre si por questões territoriais e chega determinado momento em que o pacífico Vale do Vento se vê obrigado a fazer parte dos conflitos sob a ameaça de um povoado vizinho que toma os seus recursos naturais para implementar armas de fogo.

Assim, Nausicaä parte em uma aventura para descobrir o porquê da existência do Mar do Declínio e uma forma de encontrar a paz entre as nações para proteger o futuro de seu vilarejo.

O filme, além de ter recebido o selo de reconhecimento da WWF (World Wide Fund for Nature), mostra como esse futuro imaginário pode muito bem chegar a ser a realidade do nosso planeta um dia, principalmente se continuarmos com os nossos índices de consumo devastadores. Além de mostrar a importância e eficiência de fontes de energia renováveis, o filme também faz com que o telespectador reflita sobre o quão danosos e nocivos podem ser as ações humanas sobre a natureza. Mas que, no entanto, através de uma mudança de postura perante o meio ambiente nem tudo estará perdido. Nausicaä mostra para o espectador assim como para as outras personagens da história que a sobrevivência humana depende somente dos próprios humanos e de como eles escolhem se relacionar com a natureza e fazer uso de seus recursos para viver. Temos a capacidade de interferir no ambiente em que vivemos, fazendo-o ficar cada vez melhor. 


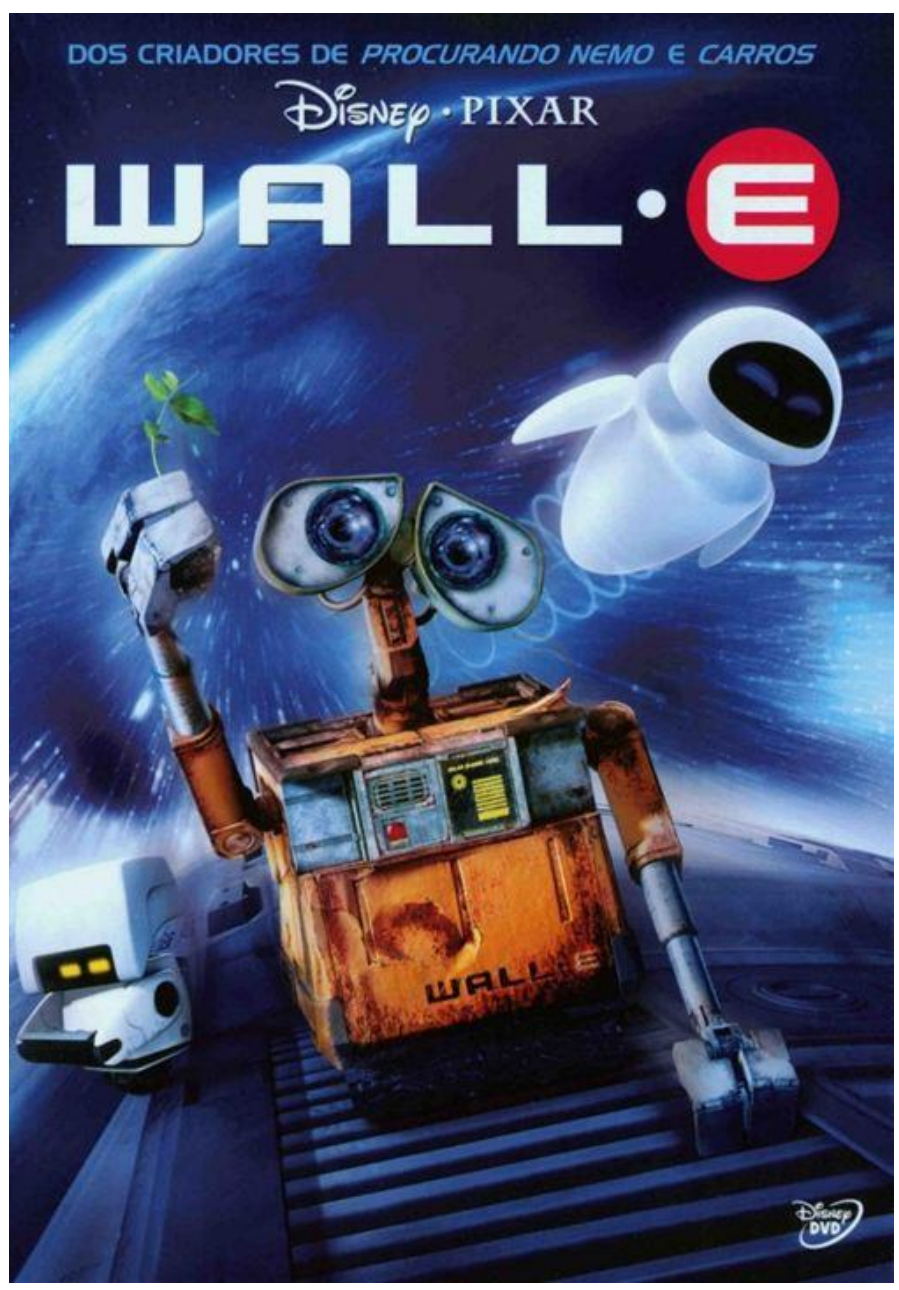

Poster do filme "WALL-E", 2008, dirigido por Andrew Stanton

WALL-E é mais um filme que, assim como Nausicaä do Vale do Vento, nos apresenta um futuro imaginário de como a Terra pode ficar caso os seus recursos continuem sendo consumidos de forma mais acelerada do que ela os pode prover.

O filme se passa no ano de 2700 quando os humanos já poluíram tanto a Terra que sua superfície se tornou inabitável, com grande presença de gases tóxicos e lixo para todos os lados. Com isso, graças ao grande avanço da tecnologia, a empresa BNL, evacuou os humanos da Terra os levando para viver temporariamente na estação espacial "Axiom", onde eles teriam todo o conforto necessário para sobreviver e se divertir. Durante esse tempo, que inicialmente seria de 5 anos, a Terra seria deixada sob o cuidado de robôs para realizarem a limpeza do planeta e amenizar os danos causados pela ação humana. Contudo, a situação do planeta já estava tão precária que esses 5 anos acabaram se tornando 700 . 
Devido a essa grande mudança nos planos a maior parte dos robôs que estavam na Terra para cuidar da limpeza foram danificados restando somente um, o WALL-E. Que, deixa de ser o único robô na Terra quando a sonda EVA (Examinadora de Vegetação Alienígena) é enviada pela BNL a fim de verificar se o planeta já encontra-se habitável, procurando por qualquer sinal de vida. WALL-E encontra no meio do lixo uma pequena planta fazendo com que EVA a colete e uma nave volte para buscar ela pro espaço e WALL-E acaba indo junto.

Ao chegarem na estação espacial, o filme também nos apresenta questões como a dependência tecnológica e o sedentarismo dos humanos, que ao longo de todos esses 700 anos acabaram se tornando pessoas obesas e com dificuldade para realizar ações simples do dia-a-dia dependendo totalmente do auxílio dos robôs.

WALL-E e EVA passam a maior parte do filme tentando entregar a planta para o sistema da estação espacial, para mostrar que a Terra ainda pode ser habitada, mas são constantemente atrapalhados por alguns robôs que, ao perceberam a influência e controle que exerciam sobre os humanos, não queriam mais que eles voltassem para a Terra. Os humanos começam a perceber o quão conformistas e indiferentes tem sido com o planeta durante todos esses anos ao tomar conhecimento de seu estado atual e percebem que se quiserem voltar a habitá-la tudo somente irá depender deles e suas ações.

O filme também mostra o quanto a tecnologia não precisa ser inimiga da natureza, mas sim a sua maior aliada. Quando os humanos enfim retornam para a Terra ao lado dos robôs eles começam a reconstruí-la para a habitação, plantando e cultivando juntos de forma que o planeta pudesse se recuperar ainda mais rápido. Além disso, reflexões importantes acerca de um consumo mais responsável ficam evidentes ao longo de toda a trama do filme.

\section{Conclusão}


Além dos filmes apresentados ainda existem muitos outros que abordam questões ambientais como tema de suas histórias e que são capazes de gerar a reflexão para uma relação mais responsável e consciente com a natureza. Constata-se também a importância da animação como ferramenta de debate e ensino de questões tão importantes para a formação dos indivíduos. Através da imersão do telespectador nos filmes, o aprendizado se torna mais fácil graças a sua melhor compreensão sobre os assuntos abordados.

\section{Referências}

- Monolice. A QUESTÃO AMBIENTAL PARA O STUDIO GHIBLI. Disponível em: <http://site.studioghibli.com.br/2010/02/27/aquestao-ambiental-para-o-studio-ghibli/>. Acesso em: 10 abr. 2018.

- MIANECKI, Julie. Top Ten Kids' Movies With a Green Theme: Loggers, hunters, developers, fishers, polluters and whalers are the evil villains in this movie genre. Disponível em: $<$ https://www.smithsonianmag.com/science-nature/top-ten-kidsmovies-with-a-green-theme-19409104/>. Acesso em: 22 abr. 2018.

- OWENS, Connor. Eco-Anime: Six Movies with Ecological Themes, Tropes, and Messages. Disponível em: <https://solarpunkanarchists.com/2016/02/19/eco-anime-sixmovies-with-ecological-themes-tropes-and-messages/>. Acesso em: 23 abr. 2018.

- NOBREGA, Hamilton. O CINEMA INFANTIL E A CONSCIÊNCIA AMBIENTAL: REFLEXÕES ACERCA DO FILME WALL-E E SUA UTILIZAÇÃO EM SALA DE AULA. Disponível em: $<$ http://www.artigos.com/artigos/10285-o-cinema-infantil-e-aconsciencia-ambiental-reflexoes-acerca-do-filme-wall-e-e-suautilizacao-em-sala-de-aula>. Acesso em: 25 abr. 2018.

- Billrosethorn. Nausicaa: Eco-Warrior of Life. Disponível em: $<$ https://billrosethorn.wordpress.com/2013/01/13/nausicaa-ecowarrior-of-life/>. Acesso em: 25 abr. 2018. 
- J, Bruno. Nausicaa - A Princesa do Vale dos Ventos.

Disponível em:

<http://sublimeirrealidade.blogspot.com.br/2013/03/nausicaa-

princesa-do-vale-dos-ventos.html>. Acesso em: 27 abr. 2018.

- ARAGUAIA, Mariana. O FILME WALL-E. Disponível em:

$<$ https://educador.brasilescola.uol.com.br/estrategias-ensino/o-

filme-walle.htm>. Acesso em: 28 abr. 2018. 